\title{
A distribuição da terra, a organização da família camponesa e a produção no município de Patzicía, $\mathrm{CH}$, Guatemala
}

\author{
The distribution of land, the organization of the peasant family and production in the municipality of Patzicia, $\mathrm{CH}$, \\ Guatemala
}

\section{Eddy Tocón Ajsivinac $ه$ (iD}

Departamento de Geografia, Instituto de Filosofia, Ciências Humanas e Sociais, Recebido (Received): 26/04/2021 Universidade Federal do Amazonas, Manaus, AM., Brasil Aceito (Accepted): 30/09/2021

*E-mail para correspondência: edestoaj@hotmail.com

Resumo: Este artigo apresenta e discute, apoiado em um caso empírico, um dos elementos centrais na conceituação do campesinato: a terra. A partir dessa discussão, aborda-se a família camponesa, seus processos de produção e reprodução social. Ademais, discute-se o panorama geral da distribuição espacial da atividade agrícola e, como consequência, o acesso e a disposição da terra no município de Patzicía, pois expressam a maneira pela qual a lógica do mercado capitalista global, não apenas penetrou, e penetra, nas comunidades locais, mas também configura e medeia as relações dentro e fora da unidade camponesa, ou seja, a organização interna da unidade camponesa e os vínculos e relações com seus arredores sociais e físicos. Nesse contexto, para os camponeses, o acesso à terra se torna difícil, quando não impossível. O objetivo do presente artigo é apresentar uma contextualização sobre a distribuição capitalista dos meios de produção, principalmente da terra, suas consequências na precariedade e a transformação da vida das famílias camponesas, assim como as respostas e possíveis alternativas que eles têm no nível local. Sobre a perspectiva metodológica que se seguiu neste estudo, foi escolhida a qualitativa, com base etnográfica a partir de um estudo de comunidade. Logo, a comunidade de estudo consistiu nas famílias camponesas, no município de Patzicía, $\mathrm{CH}$, Guatemala.

Palavras Chaves: Terra; campesinato; capitalismo; agricultura.

Abstract: This article presents and discusses, from an empirical case, one of the central elements in the concept of peasantry: the land. From this discussion, the peasant family, its production and social reproduction processes are approached. It addresses the general view of the spatial distribution of agricultural activity and, as a consequence, the access and disposition of land in the municipality of Patzicia, as they express the way in which the logic of the global capitalist market not only penetrated, and penetrates, the local communities, but it also configures and mediates the relations inside and outside the peasant unit, that is, the internal organization of the peasant unit and the bonds and relations with its social and physical surroundings. In this context, for peasants, access to land becomes difficult, if not impossible. The objective of the article is to present a contextualization about the capitalist distribution of the means of production, mainly of the land, its consequences in the precariousness and transformation of the peasant families live, but also the answers and possible alternatives that the peasants have at the communal level. The methodological perspective that followed in this study was qualitative with an ethnographic basis from a community study, where the community of study was the peasant families in the municipality of Patzicia, CH, Guatemala.

Keywords: Land; peasantry; capitalism; agriculture.

\section{Introdução}

O acesso à terra é uma condição necessária para a reprodução camponesa. Nesse sentido, Shanin (1976) salienta que a posse e disponibilidade de terra é necessária e suficiente para a sua produção e reprodução. A importância da terra como fator de produção é evidente quando a agricultura camponesa é entendida como 
uma articulação específica dos recursos naturais e da sociedade. À vista disso, é possível perceber que a relação que o camponês, em um determinado contexto, mantém com a terra pode facilitar a reprodução social ou levar a uma crise agrária (PLOEG, 2010), esta última ocorre se o acesso à terra pelo campesinato é complicado ou impossível.

O presente estudo tem o objetivo de discutir a importância da terra em - e por isso de - as unidades camponesas e as características que ela assume no atual contexto de expansão do capitalismo neoliberal que essas comunidades enfrentam. Nessa conjuntura, apresenta-se uma discussão que toma como ponto de partida um estudo realizado no município de Patzicía, CH, Guatemala, entre os anos de 2016 e 2017, com a finalidade de fornecer contribuições para enfrentar e continuar o debate sobre a questão da terra, a disposição dos meios de produção, a soberania alimentar, as mudanças ambientais e o papel do campesinato, como uma alternativa real e imediata à organização capitalista, e como uma crítica às consequências do capitalismo mundializado, tanto na Guatemala quanto na América Central.

Nesse contexto, a dinâmica do mercado global é influente, se não decisiva, nas relações sociais em que penetra. Em um cenário de distribuição desigual de terras e penetração do capitalismo global, como o encontrado no município de Patzicía, a provisão de terras, mesmo no mercado, é difícil. A esse respeito, Shanin (1976, p. 23) escreveu: "la provisión de la tierra en el mercado es muy limitada e inflexible en términos del mismo mercado, o totalmente nula" (1976, p. 23). O caso ilustrado neste artigo parece provar que a proposição está correta.

Para as famílias camponesas de Patzicía, a relação particularmente desvantajosa do acesso à terra dificulta sua reprodução social, como é suposto. A terra apresenta o fenômeno da pulverização, em primeira instância, devido ao crescimento natural da família. Porém, o acesso à terra é mediado pelo mercado, que finalmente determina a oferta desse meio de produção.

Este estudo começa com uma visão contextual sobre a distribuição da terra e o fenômeno da pulverização que ela apresenta no município de Patzicía. Na seção intitulada $O$ mercado e a distribuição de terras é abordada a questão do fornecimento de terras no mercado e as características particulares que isso apresenta em Patzicía. Em seguida, nas seções intituladas $O$ arrendamento de terras e Terras municipais são discutidas as opções de acesso à terra que os camponeses à beira da pobreza no município têm, dentro do contexto da globalização capitalista e de suas expressões locais no município. E em A circulação da terra por herança são levantadas as dimensões não econômicas que a terra possui no campesinato, para poder finalizar fazendo algumas considerações sobre a discussão apresentada. Mas, antes disso, são expostos os procedimentos metodológicos seguidos na pesquisa.

\section{Materiais e métodos}

A perspectiva metodológica que se seguiu foi a qualitativa, com base etnográfica, a partir de um estudo de comunidade. Ademais, a estratégia de pesquisa refere-se a abordar o problema na perspectiva de um estudo de caso, ou seja, a pesquisa de comunidade assume-se como um grupo delimitado, segundo o ator social, neste caso específico: o camponês no contexto da globalização capitalista no município de Patzicía, Chimaltenango.

A etnografia indutiva é um instrumento essencial para coletar dados empíricos por meio dos atores imersos em determinadas dinâmicas sociais. Nesse viés, permite construir interpretações da sociedade a partir de uma base empírica. De acordo com Pujadas (2010), a principal tarefa da etnografia é a abordagem da realidade social, através dos próprios atores, para imergir naquele mundo de significados e sentidos. Desse modo, a importância da abordagem etnográfica está na capacidade de compreender a estrutura, dinâmica e funcionamento social, só que a partir das subjetividades de seus membros, postas em diálogo com uma interpretação teórica. Nessa perspectiva, para Girona (2010), os estudos de comunidade consistem em um procedimento de pesquisa, que necessariamente se enquadra em uma construção conceitual de comunidade. Essa noção é essencial na delimitação abstrata do problema de pesquisa. Nesse sentido, o termo comunidade diz respeito a um nível micro baseado em certos conceitos e apreciações de totalidade, homogeneidade e condicionamento material, os quais ajudam a delimitar a comunidade de estudo. Assim, a comunidade de estudo são as famílias camponesas de Patzicía.

Os critérios de seleção dos atores-chave, em um estudo qualitativo, passaram pelas características diferenciadoras (como construção abstrata), que possuem como membros de uma comunidade de estudo. Nessa pesquisa, as principais características de seleção dos atores-chave foram: (a) que a extensão da terra que cultiva não exceda as 4 cuerdas $(0,45$ ha) em média, houve casos em que a extensão da terra cultivada excedeu essa média, mas isso foi ignorado quando a seguinte característica foi atendida; (b) que pertençam a 
uma família de agricultores que utilizavam sua produção agrícola exclusivamente para consumo próprio (e parcialmente para comercialização); e (c) que, além do exposto anteriormente, eles tenham as atividades agrícolas como seu principal meio de autoconsumo. Por último, a principal razão pela qual foi escolhido o município de Patzicía é a importância da atividade agrícola do município no nível nacional como produtor de hortaliças.

Sobre a terra, procurou-se atingir a questão de como a disponibilidade ou ausência de terra afeta a reprodução social da família camponesa, e de que forma se organiza nesse contexto. Propôs-se, então, a realização de entrevistas e análise de informação secundária, com base em roteiros de entrevista, observação direta e fichas de conteúdo. Além de cadernos de campo e fichas de conteúdo, os dados foram coletados por meio de arquivos fotográficos e gravações de áudio.

Com a construção de uma etnografia, pretende-se elaborar um discurso acadêmico para aprofundar o conhecimento da ação social, por intermédio de um material empírico, que só faz sentido na medida em que entra em diálogo e é mediado pela uma teoria de intepretação da realidade social. Logo, foram realizadas 22 entrevistas, das quais 12 foram com camponeses, 3 com empresários agrícolas locais, 3 com lideranças locais e 4 com especialistas no tema de campesinato e lideranças camponesas nacionais, no período de novembro de 2016 para março de 2017.

Em relação à informação secundária, a informação estatística na Guatemala é escassa, incompleta e às vezes anacrônica. Nesse sentido, não foi possível aceder a dados oficiais atualizados, pois o último Censo Agropecuário Nacional (ou IV Censo Agropecuário) corresponde ao ano de 2003, e embora seja um censo bastante completo, a metodologia utilizada é anacrônica (fato admitido pelo INE próprio). Ademais, os dados, no censo, não são apresentados em unidades de medida padrão, o que torna a análise difícil e tediosa. Neste relatório, são apresentados os dados em unidades de medida padrão e foi colocado em comparação às unidades de medida "guatemaltecas", pois sua especificação é importante para a análise. Além disso, no altiplano central e ocidental da Guatemala, ainda são usadas unidades de medida de área de origem colonial. Por exemplo, 1 cuerda é uma unidade de medida de área de origem castelhana colonial, não é uma medida padrão. Já no município de Patzicía 1 cuerda média é equivalente a 40x40 varas (também de origem castelhana colonial), que é igual a $1.118,23 \mathrm{mts}^{2}$ ou 0,11 ha. Dentre essas unidades de medidas estão: Cuerda, Manzana (7 cuerdas ou 0,69 ha), Caballería (64 mz ou 44,7 ha); e unidades de massa, como Quintal guatemalteco (100 lb ou $46 \mathrm{~kg})$.

Por fim, os dados estatísticos mais recentes disponíveis, embora não oficiais, para o município de Patzicía, estão no Diagnóstico Sociotécnico realizado pela Faculdade de Ciências Econômicas e Sociais da USAC, levantados em 2009 (LOPÉZ, et al., 2011).

\section{Resultados e discussões}

\subsection{Distribuição de terras no município de Patzicía, uma visão contextual}

Em termos gerais, "as terras", no município de Patzicía, são distribuídas em próprias, arrendadas e "emprestadas". Os dados quantitativos mais recentes disponíveis são os de Diagnostico socioeconómico, potencialidades productivas y propuestas para inversión (LÓPEZ et al.) do ano 2011, segundo os autores, $52,37 \%$ da posse da terra é na forma de propriedade; $44,29 \%$ é arrendada e os 3,34\% restantes correspondem às terras comunais ou municipais ("emprestadas"). Essa pesquisa faz uma comparação com o IV Censo Agropecuário Nacional do Instituto Nacional de Estatística - INE -, e conclui que a quantidade de terras arrendadas tem aumentado desde 2003. Naquele ano, o percentual de terra arrendada era de apenas 4,73\%, contra 92,24\% do uso da terra em forma de propriedade, como se pode ver na Figura 1.

Atualmente, a distribuição de terras no município, em unidades de medida, está presente em: microfazendas (até 0,7 ha), fazendas subfamiliares (até 7 ha) e fazendas familiares (até 44,7 ha). De acordo com dados do Diagnostico Socioeconómico, 50\% das terras aráveis são microfazendas, enquanto as fazendas familiares em proporção são equivalentes a 16,07 ha cada (LÓPEZ, et al., 2011, p. 48), em média. Um fato importante, segundo o III e IV Censo Agropecuário Nacional de INE, correspondente aos anos de 1979 e 2003, no município havia fazendas multifamiliares de médio porte (de 44,7 ha a 894,4 ha) e fazendas multifamiliares grandes (894,4 ha ou mais). Já no ano de 1979, 10,87\% da área do município eram de fazendas multifamiliares de tamanho médio, equivalente a 434,40 ha; e 44,59\% da área compreendiam fazendas multifamiliares grandes, equivalentes a 1.782,09 ha. Em 2003, 4,31\% eram fazendas multifamiliares de tamanho médio, que totalizaram 116,22 ha; e 22,54\%, fazendas multifamiliares grandes, o que seria 607,81 ha. Hodiernamente - pelo menos a partir de 2009 -, fazendas de tais magnitudes não estão 
registradas no município. Nesse contexto, é possível observar uma desconcentração de terras causada pelo crescimento populacional, por um lado, e falta de poder de compra, por outro, como visto na Figura 2.

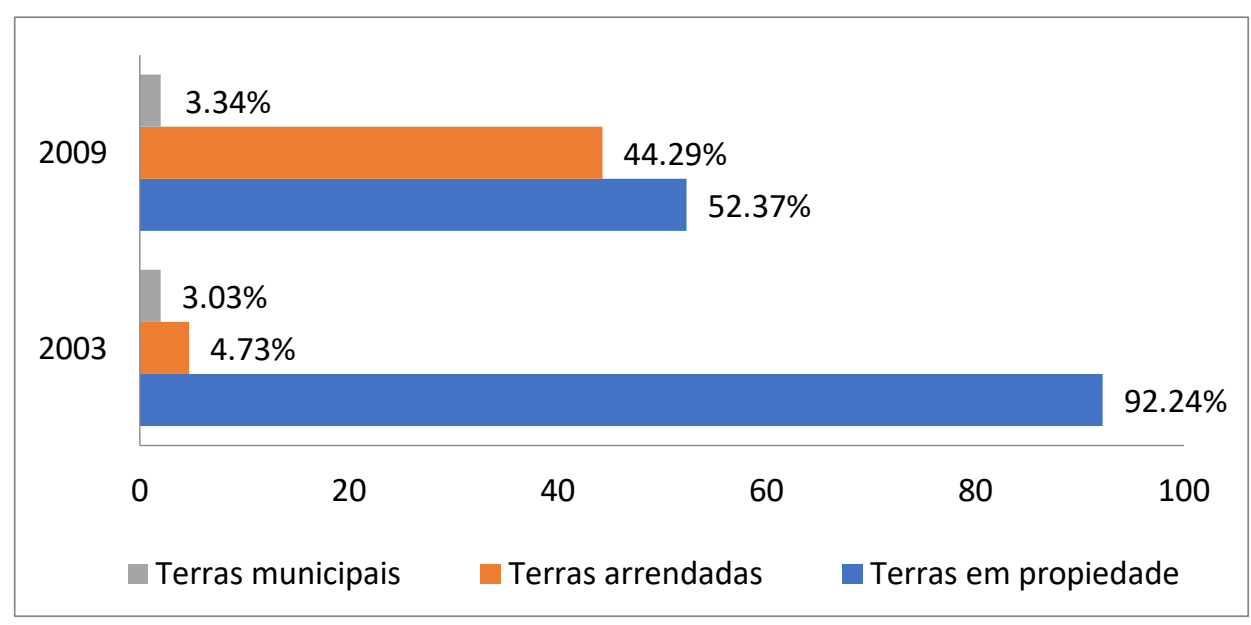

Figura 1: Acesso, uso e propriedade da terra em Patzicía, anos 2003 e 2009. Fonte: Elaboração própria com base nos dados de López et al. (2011) e INE (2004).

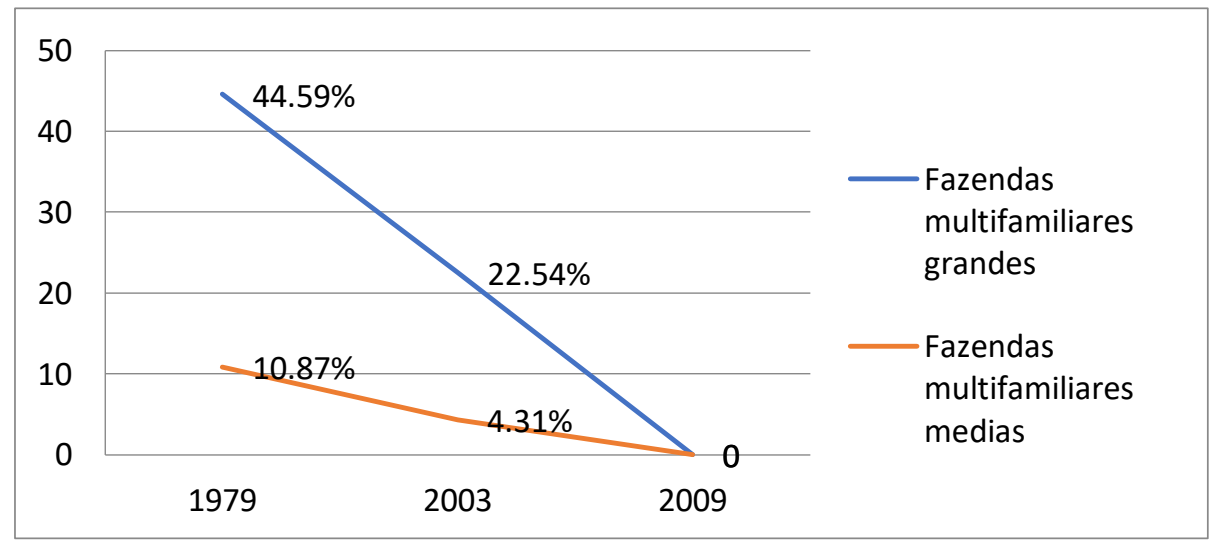

Figura 2: Desconcentração de terras no município de Patzicía de 1979 a 2009. A figura mostra a desintegração das fazendas familiares médias e grandes desde 1979 a partir da porcentagem da área do município que ocupavam. Fonte: Elaboração própria com base nos dados de López et al. (2011) e INE (2004).

Na primeira metade do século XX, havia 19 proprietários com considerável concentração de terras no município, entre 89,45 e 1.341,70 ha. Uma lista detalhada dos proprietários dessas fazendas pode ser acessada em Elite ladina, vanguardia indígena: de la intolerancia a la violencia en Patzicía 1944 (RODAS e ESQUIT, 1997, p. 42). Embora hoje não haja grandes concentrações de terra (PÉREZ et al. 1991), e ao invés disso pareça que grandes propriedades estão se desintegrando, vale a pena perguntar: por que alguns camponeses que trabalham nas terras não têm essa propriedade?

\subsection{A falta de terra em Patzicía}

Pode-se observar com este estudo, que o camponês no município não tem mais a opção de acesso à terra. Para a unidade camponesa, a terra continua a ser parcelada devido ao efeito do crescimento da família, sem mencionar aqueles que não contam mais, ou que nunca tiveram um terreno para cultivar. Para muitas famílias camponesas isso se traduz no arrendamento da terra para organizar a produção. No centro do discurso dos camponeses sobre as maiores dificuldades que enfrentam para levar adiante a sua atividade agrícola está a terra, a falta dela no município e o acesso por meio de arrendamento também começa a ser difícil. A posse e/ou disponibilidade da terra, segundo o tipo de acesso (arrendamento, compra, invasão), configura a atividade econômica de toda a unidade camponesa (SHANIN, 1976). 
Com base nisso, questiona-se como é organizada a unidade camponesa, se não há possibilidade de mais terra. E, para os propósitos desta pesquisa, mais importante ainda, indaga-se por que não há possibilidade de mais terra. A primeira pergunta pode ser respondida com a dinâmica da mobilidade laboral, na qual os membros da família camponesa entram no caso estudado de Patzicía. Isso porque, no momento em que não há mais possibilidade de terra, a força de trabalho da família camponesa é regulada pelos membros que deixam a família (SHANIN, 1976, pp. 21-22; CHAYANOV, 1974, p. 124) como empregados assalariados. A segunda questão pode ser respondida pensando na dinâmica do crescimento populacional, mas não é a única resposta. Por outro lado, devido às demandas do mercado, a terra também é limitada em termos de acesso.

Nesse viés, devido à dinâmica do crescimento populacional, a divisão da terra é praticamente impossível. Esse é um problema real e imediato para os camponeses. No município, desde o início da década de 1980 anos de liberalização global do mercado -, isso foi exacerbado, segundo dito pelos camponeses, eles viram como a terra é cada vez mais limitada e isso tem um impacto direto em sua organização social.

A partir da observação de campo, realizada em 2016-2017, a maioria das famílias rurais do município não obteve acesso à terra por herança. Esse fato coincide com a introdução da produção de hortaliças para exportação (produção feita por camponeses locais sob contrato com empresas estrangeiras), uma produção não-tradicional no município, a qual modificou toda a dinâmica da posse e acesso à terra dessa comunidade camponesa e indígena de culturas tradicionais, como foi Patzicía, até a década de 1970.

Dessa forma, no município de Patzicía, a impossibilidade de acesso à terra se deve a determinantes externos da própria dinâmica camponesa. A falta de poder de compra do camponês, juntamente com os altos preços da terra no município, faz com que esses produtores vejam o acesso à terra banida por meio da compra, um camponês, em entrevista realizada em 2016, afirma:

Me estaba comentando una persona de acá del pueblo, porque ellos tienen terreno acá en el bosque, y en el bosque una cuerda de terreno vale como veinte mil quetzales [USD 2.596,02], aquí [en Patzicía] sí todavía hay terrenos de ese precio pero están en lugares ya retirados, ahora los terrenos aquí ya no tienen ese precio de veinte mil quetzales (Entrevista C01E01I, 08/11/2016).

Pode-se perceber, que a falta de poder de compra dos camponeses e os altos preços são dois lados da mesma moeda, que se devem à imersão do município na produção de hortaliças para o mercado. A economia de autoconsumo, à qual o camponês está sujeito, coexiste com a desigualdade social no nível local. Neste momento e condições, embora o camponês queira expandir sua produção não é possível, principalmente porque não há possibilidade de acesso a meios produtivos; isto é, se não tem acesso à terra é simplesmente impossível. Um camponês entrevistado explica:

En primer lugar, aunque uno quiera sembrar un poco más no se puede porque no hay terreno, no tenemos terreno propio. Otra cosa, que saliéramos a buscar para arrendar ya no se consigue, porque la mayoría tiene un su poquito de terreno que cada quien le sirve lo poco que tiene, de esa manera aquí en Patzicía terreno ya no hay (Entrevista C01E04, 27/01/2017).

Logo, quando uma unidade camponesa é incapaz de acessar a terra, as opções que ela tem são duas: arrendar terra ou entrar na dinâmica da mobilidade do trabalho. Tendo em vista a questão do por que não há possibilidade de mais terras, observa-se que a sua distribuição no município tem sido determinada, desde a década de 1980, pelas demandas relacionadas à produção de hortaliças para o mercado (PÉREZ, et al. 1991).

\subsection{O mercado e a distribuição de terras}

A maneira de responder à pergunta sobre as razões pelas quais não há possibilidade de mais terra e, portanto, possibilidades de expandir a produção, é baseada no conhecimento das demandas do mercado. Enquanto Patzicía está imerso na dinâmica da produção agrícola para o mercado, o acesso à terra é regulado por ele, e limitado para os camponeses. Em 2009, por exemplo, os volumes de produção, em Patzicía, de repolho e cenoura, hortaliças com os maiores volumes de produção no município, foram 2.925,67 t e 671,32 t, respectivamente, enquanto a quantidade de milho foram 233,37 t (LÓPEZ et al., 2011, p. 105). Para a área de 23,54 ha, de repolho e cenoura, entre microfazendas e fazendas subfamiliares. Esse fato, por si só, não diz muito, mas os efeitos podem ser encontrados no discurso dos camponeses, quando falam sobre a disponibilidade da terra, que praticamente está toda ocupada, devido à sua alta produtividade, como se ouve 
do discurso dos camponeses. Pode-se dizer que Patzicía possui terras altamente produtivas, por isso é difícil encontrar terras para arrendar e/ou comprar, pelos custos que representa.

O fato de haver esses altos volumes de produção em Patzicía, com altos valores de produção, significa que as terras aráveis, que são naturalmente limitadas, são mantidas "monopolizadas" pelos arrendantes kulaks e agricultores empreendedores capitalistas, ou que o preço de compra/venda seja muito alto, o que impossibilita que qualquer camponês possa acessá-lo. Obviamente, não é uma relação de causa-efeito, pendular e mecânica. Porém, por causa da alta produtividade, que torna desejáveis certas terras em Patzicía, os camponeses que agem sozinhos não têm acesso a terras ou terras de qualidade. Nesse contexto, a possibilidade de acesso a ela é reduzida e, além disso, eles também não encontram acesso a mercados mais equilibrados, porque sem pelo menos uma organização camponesa produtiva, como a cooperativa, não há muitas possibilidades de acesso ao mercado e a meios produtivos em geral.

Os camponeses dizem que, apesar de tudo, pode-se viver, sua própria existência o demonstra, mas com essas características da distribuição da terra eles não têm mais perspectiva do que a subsistência:

Bueno, legalmente, para pasarla se puede, pero para pensar uno de superar, de comprar algo de valor, entonces algo ya difícil. Si por ejemplo uno piensa: ahora voy a comprar una cuerda de terreno, voy a comprar un pedazo aquí. Ya difícil, ya quiere ganas, ya no se puede. Ya ahora si nos damos cuenta que todo está caro, un lote vale unos sesenta mil, cincuenta mil [GTQ]. Ya para juntar una cantidad de pisto [dinero] solo con la siembra quiere ganas, ya no se puede. Hay unos que sí tal vez, pero los que tienen propio terreno, digamos unas diez, quince cuerdas, todavía tienen terreno bastante. Ahí sí puede hacer algo porque lo que entra en las manos ya no lo saca para pagar arrendamiento (Entrevista C01E02, 17/01/2017).

Com a observação da realidade agrária do município, é possível perceber a impossibilidade de acesso à terra, o que não ocorre justamente pela natureza limitada desse meio de produção, pressionado pelo crescimento populacional, pelo menos não apenas por isso. Embora esse seja o problema que impossibilita, em certo sentido, a continuação da divisão fundiária local, e por esse motivo promove-se parcialmente a mobilidade do trabalho e a expulsão das gerações mais novas para outros tipos de atividades econômicas. A impossibilidade de acesso à terra é finalmente determinada pela alta produtividade agrícola do município, uma consequência de seu contato e da lógica do mercado, que, primeiro, torna o preço da terra alto demais, praticamente inacessível aos camponeses pobres, e, segundo, sua extensa e agora normal ocupação para a produção de hortaliças de exportação. Em um contexto de forte crescimento populacional, a pequena produção camponesa perde lugar, força e apoio dentro da mecânica do mercado.

\section{4. $O$ arrendamento de terras}

Cuando no se tiene terreno se alquila... Se alquila y se complica más la vida porque casi todo lo que uno se queda un poco de la ganancia, digamos, hay que pagar la tierra (Entrevista C01E02, 17/01/2017).

O $50,47 \%$ das unidades produtivas no município corresponde a microfazendas. E do total dessas microfazendas, a área equivalente a 55,73 ha foi usada para a produção de milho, ou seja, $69,35 \%$ do total de terras em microfazendas, como se vê na Figura 3. Levando em conta os volumes de produção relativamente baixos desse grão em áreas tão grandes de terra, a importância que este tem para pequenos produtores e camponeses é vista. Por exemplo, em 2009, o volume de produção de milho para 55,73 ha foi de 217,05 t; enquanto os volumes de produção de repolho e cenoura, juntos, foram 4.409,37 t, cerca de 24 vezes maior, em uma área de terra quase três vezes menor, 18,98 ha (LÓPEZ et al., 2011, p. 106).

Isso se explica pela importância cultural do milho nas famílias camponesas do município, independentemente da origem e filiação étnica de acordo com dados de campo. No entanto, da produção total de milho, apenas $10 \%$ é comercializado localmente, o restante é destinado ao autoconsumo (LÓPEZ et al., 2011, p. 119).

A produção camponesa no município concentra-se em milho e feijão, porque essa é a base da alimentação e tem uma forte base cultural pré-hispânica; a produção de hortaliças pode ou não ocorrer. Métodos e tecnologias tradicionais são usados para isso, e a forma de financiamento é baseada nos mesmos ciclos de comercialização tradicionais desses grãos. 


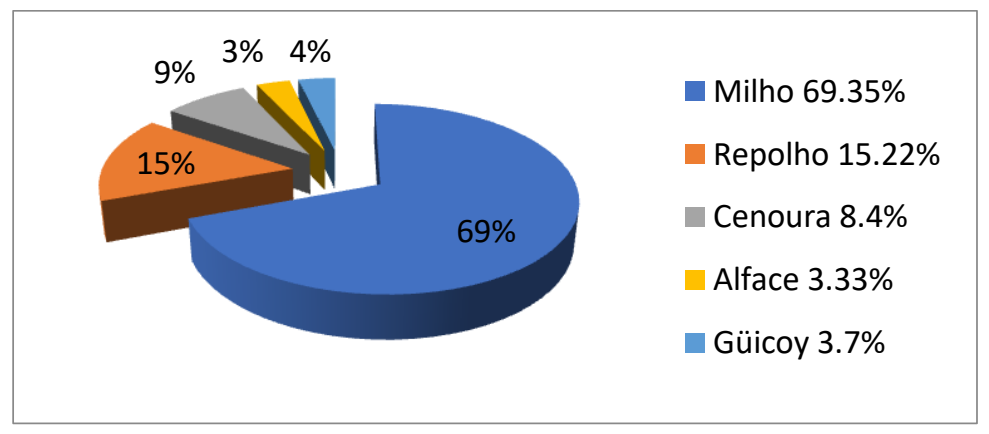

Figura 3: Porcentagens de produção sobre o total de microfazendas, ano de 2009. Fonte: Elaboração própria com base nos dados de López et al. (2011).

A importância cultural do milho é a maneira pela qual é explicado que a terra de todos os agricultores no município, na forma de propriedade, é usada para o cultivo de grãos. Nesse sentido, em todas as entrevistas realizadas, os atores, incluídos kulaks e empreendedores agrícolas capitalistas locais, afirmam usar sua própria terra (quando eles possuem) para cultivar milho. E, naqueles casos em que um agricultor quer expandir sua produção com o cultivo de hortaliças, especialmente no caso dos empreendedores agrícolas, a terra arrendada é usada com esses objetivos.

A necessidade de arrendamento de terras pelos camponeses geralmente se deve à procura de recursos extras, principalmente porque a produção de grãos por si só não é suficiente nesse contexto em que a família camponesa não possui os recursos suficientes para cobrir suas necessidades básicas, insumos agrícolas e, por outro lado, as dívidas em geral, conforme evidenciado nestas expressões:

Bueno, al menos nosotros lo que hacemos es que sí tenemos un poquito de terreno, pero eso casi sólo da para la alimentación propia, ahora ya con un fin de obtener algún recurso económico lo que hacemos nosotros vemos ahí como alquilar un poquito de terreno y con ese terreno que alquilamos sí ya es con el fin de ver cómo, si se logra adquirir un poquito de recursos, ya con fines de ganancias económicas, por decirlo así. Que a veces sí se da y a veces es todo lo contrario, en lugar de ganancia es pérdida (Entrevista C01E07, 03/02/2017).

Pode-se entender que uma das razões pelas quais essa "perdida" ocorre é devido ao pagamento do arrendamiento (em torno de USD 130,35 por ano). No município, as formas tradicionais comunitárias de pagamento, que não incluíam transações monetárias, começam a fazer parte do passado, e o pagamento com dinheiro é cada vez mais comum:

Pues mi problema en este tiempo es la tierra. Porque yo casi solo estoy arrendando mi tierra. Ya para superar uno así [es] algo difícil, porque no tiene tierra, digamos propia, entonces ahí juntando un poco de pisto [dinero] se va para otro lado, lo que gano ahí se va pagando la tierra. Pagando tierra, pagando tierra, después comprando semilla, comprando abono. Cuando nomás salir la siembra empieza a comprar insecticida para fumigar, para atender todo el tiempo. Entonces casi no se le queda nada a uno [de dinero], por eso estamos bien atrasados, digamos con la familia, porque casi no tenemos terreno propio. [...] Casi muchos dicen: -ah, estamos fregados, ahora ya quiere ganas la vida -dicen. Porque peor si arrendando terrenos casi no se le queda nada a uno de ganancia, dicen. Casi la mayoría así dicen (Entrevista C01E02, 17/01/2017).

A distribuição da terra e a dinâmica em que os camponeses estão imersos os obrigam a arrendar, especialmente nos casos em que falta terra ou a quantidade suficiente para subsistir. Até a lógica desse contrato de arrendamento os colocam em desvantagem:

Un poquito arrendado un poquito propio también [de tierra], como a veces no nos alcanza también lo poquito que tenemos. Si uno amplía un poquito su siembra pues ya va queriendo para su maíz, para su frijol, y ya va queriendo otras costitas más, y en eso también ya se aumenta otro gastito, porque también el arrendamiento ya es caro, a ochocientos, hasta mil quetzales, va. Y para que vas a vender a mil [GTQ] una tu cuerda de siembra sólo para pagar, de ahí lo demás es una gran pérdida (Entrevista C01E05, 28/01/2017). 
O caso dos camponeses que arrendam terras municipais (públicas) é um pouco diferente, pois essas terras são de baixa produtividade, em comparação com o restante das terras do município. Os arrendantes das terras municipais são camponeses sem terra.

\subsection{As terras municipais}

Do terreno municipal destinado ao arrendamento, segundo dados da prefeitura sobre os pagamentos que recebe anualmente nesta rubrica: no estaleiro municipal Soko' para o ano de 2016 havia 277 inquilinos, no estaleiro Rastro 30, no estaleiro Pachut 93, no estaleiro Asoliadero, na aldeia Cerritos Asunción, 210 e no estaleiro Balam Juyú 30. O pagamento do arrendamento por 1 cuerda $\left(1.118,23 \mathrm{mts}^{2}\right.$ ou $\left.0,11 \mathrm{ha}\right)$ varia de acordo com a localização, principalmente devido às estradas e às dificuldades de acesso que possa ter. Para os terrenos do Soko', o pagamento é de GTQ 10,00 por ano por cuerda, no Rastro de GTQ 15,00, no Pachut de GTQ 12,00, no Asoliadero de GTQ 7,50 e no Balam Juyú GTQ 12,00, ou seja uma média de USD 1,54 por ano.

Em "La Montaña", ou estaleiro Soko', essas terras são usadas quase que exclusivamente para reproduzir a vida da unidade familiar camponesa. O número máximo de cuerdas concedidas a cada família é quatro $(0,45$ ha). Muitas dessas famílias combinam suas atividades agrícolas com outros tipos de atividades econômicas, como pequenas lojas e vendas em suas casas e na praça central do município. As referidas terras municipais são das que se beneficiam o maior número de famílias camponesas que vivem no centro urbano do município de Patzicía, principalmente as que residem na Zona 3 (antigo $3^{\circ}$ Cantão), devido à proximidade do estaleiro.

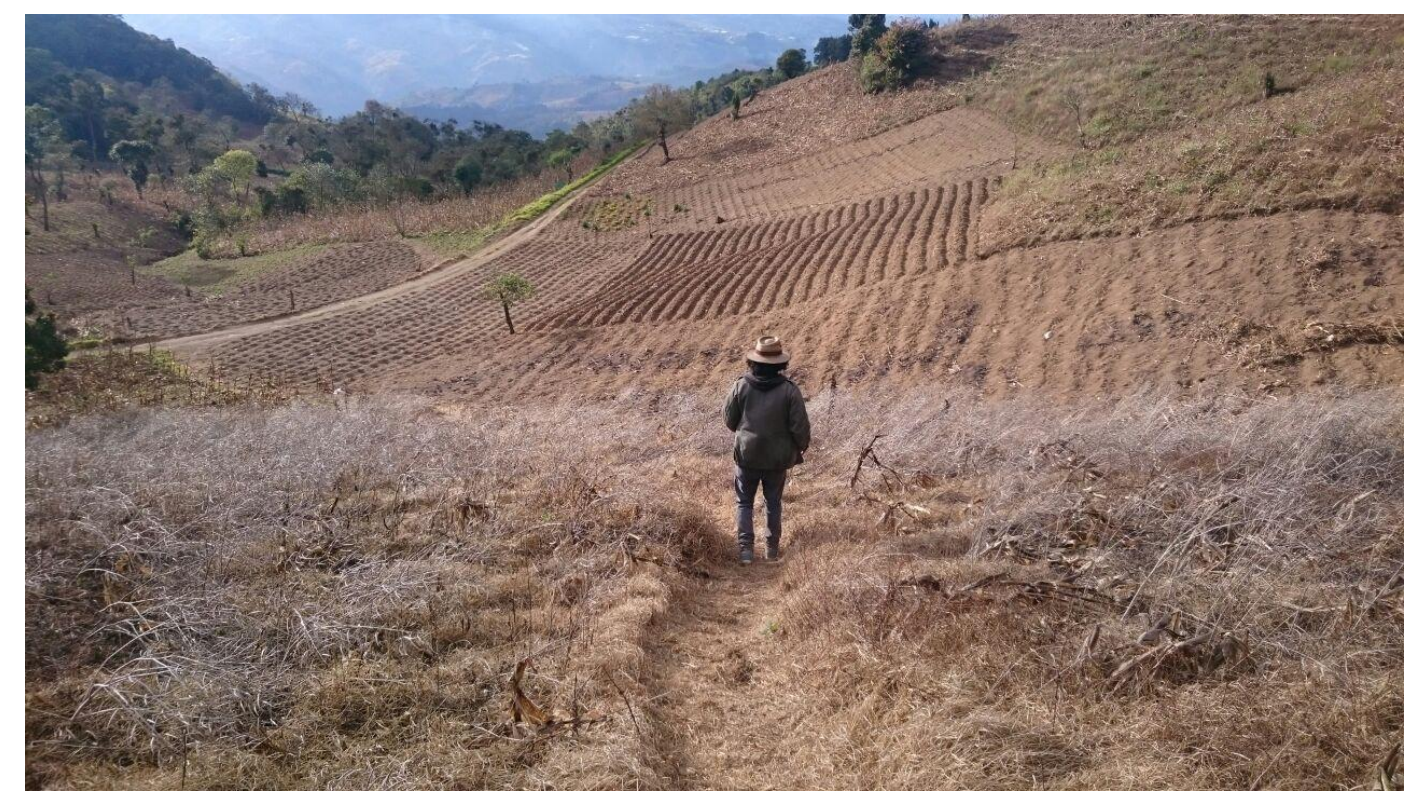

Figura 4: Terras municipais, estaleiro Soko'.

Fonte: trabalho de campo, janeiro 2017.

Esse estaleiro está localizado na montanha de mesmo nome, uma observação ao local confirma o exposto anteriormente, as plantações no local, pelo menos até 2017, eram principalmente milho, feijão e algumas legumes que não requerem a aplicação de força de trabalho intensiva, nem técnicas ou métodos intensivos de produção: güicoy, ervilha crioula, feijão verde, feijão e couve-flor crioula. As terras municipais aráveis estão todas já ocupadas. As pessoas que têm acesso a elas, por meio de arrendamento direto ou subarrendamento, têm cuidado delas. Existe uma apropriação que torna esses camponeses praticamente os proprietários, ou pelo menos eles se sentem como tais. 


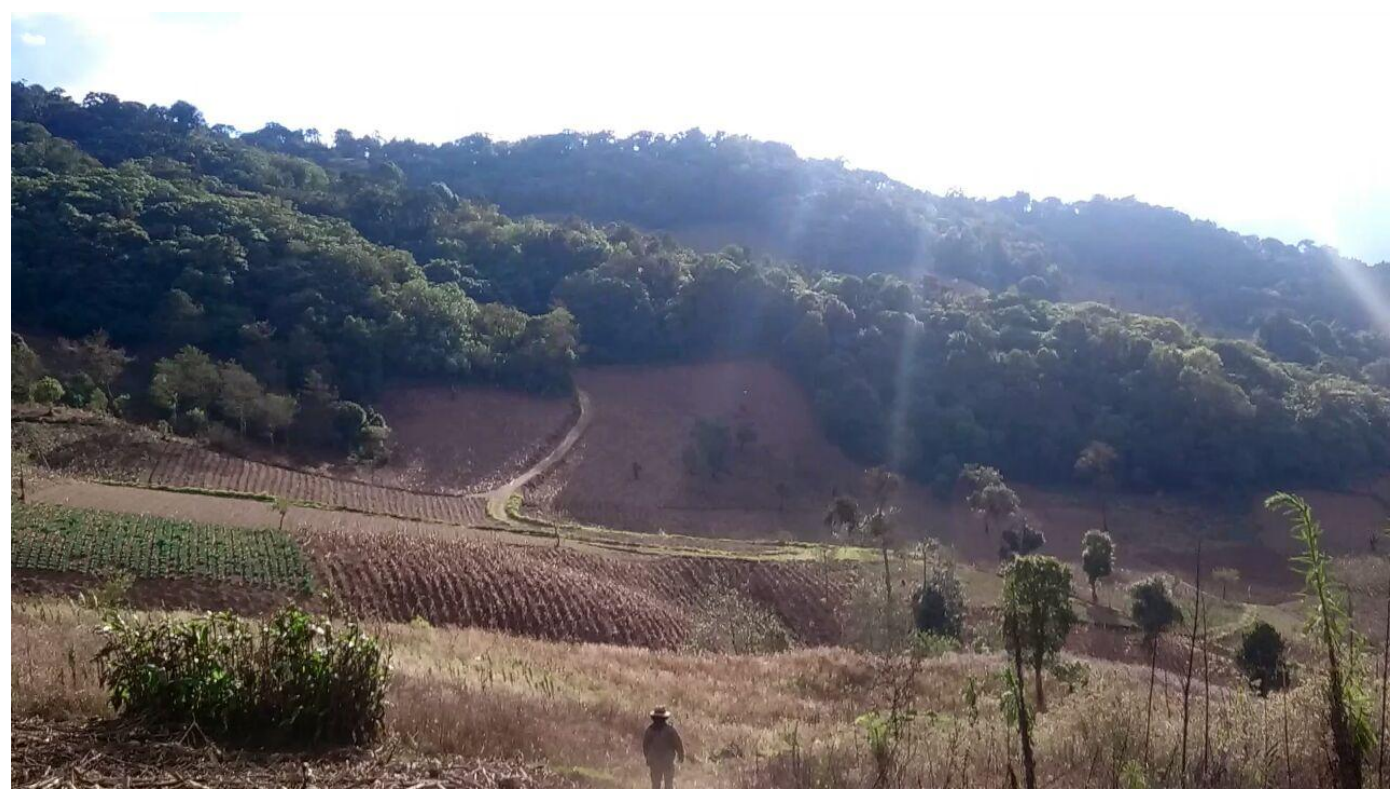

Figura 5: Estaleiro Soko'.

Fonte: trabalho de campo, janeiro 2017.

Entretanto, a incerteza do futuro está sempre presente, um dos camponeses com acesso a terras arrendadas no estaleiro Soko' salienta que:

Pero, así como aquí, casi la mayoría ya estamos fregados, porque como te estaba diciendo, ya estamos jodidos. Con el terreno quiere ganas, saber que va pasar, -taba diciendo la gente. Porque casi estamos viendo que está algo difícil la vida. Unos que otros tal vez tranquilo, que así como te digo tal vez tienen suficiente terreno. Entonces así estamos, esa es la vida de nosotros, estamos fregados, pero, así como hablamos con la gente por ahí, Dios sabe cómo pasamos la vida, tiene que luchando uno, luchando y luchando, así por así pasando la vida, pasando el año (Entrevista C01E02II, 17/01/2017).

Como causa e efeito do pequeno poder de compra do camponês e do difícil acesso à terra, resultado da dinâmica de produção para o mercado, as terras municipais, as quais esses pequenos produtores podem ter acesso, não são as mais produtivas do município. Isso porque a capacidade produtiva das unidades camponesas é afetada pelo acesso desigual de terras que essas famílias têm. Dessa forma, a dinâmica do mercado, que o Estado estimula, os expulsa da própria atividade agrária.

\subsection{A circulação da terra por herança}

Quando as famílias possuem terras para circular entre gerações subsequentes, a propriedade e o direito de uso são mantidos por linhas patrilineares de herança. Nesse contexto, sempre o homem é proprietário e administrador da propriedade da família, a exceção à regra são as viúvas sem filhos do sexo masculino ou com filhos homens muito jovens. No discurso dos camponeses do município, está presente a ideia de que os que tiveram sucesso na agricultura são os que obtiveram terras por herança, devido aos altos custos da terra no mercado.

Para as famílias camponesas do município, a herança é um mecanismo de acesso à terra fundamental na reprodução social. A partir disso, é possível construir um vínculo com os ancestrais e a história da família, ou seja, a terra possui um caráter simbólico. Os camponeses e as pessoas em geral - embora não estejam dentro da lógica da produção camponesa -, que herdaram a terra, ao falarem sobre ela, se lembram de seus pais ou antepassados, com isso é criado um vínculo simbólico com a terra. A seguir, um fragmento de uma história que exemplifica isso:

Incluso el otro cuate eso me estaba diciendo [...] -vos, yo a aquel le estaba diciendo, ayudá a tu mamá, mirá a vos te dejaron tanto terreno, porque yo me doy cuenta vos, mis posibilidades son mínimas o casi nada de que yo vaya a comprar mi propio sitio, porque donde estoy viviendo es de mis papás, cuando estaban vivos traté de darles, no fue gran cosa, pero aunque sea un vasito de atolito les ofrecía. Porque está jodido, parece que no tengo chance de algo, a cómo va la situación, va ser algo difícil que yo vaya comprar algo. 
[...] Y ese mi cuate siempre decía: -Otra parte también, por eso yo no dejo alquilado. También una de las cosas que decía el papá dice: -puchis, ni modo que ustedes entre tres van a usar ese terreno, cuánto les queda, unas 10 cuerdas, 20 cuerdas, ni modo que ustedes no van a poder trabajar 15 cuerditas y yo pude trabajar las 40, está jodido (Entrevista C01E01II, 15/11/2016).

Contudo, a herança no município, ao mesmo tempo em que possui caráter econômico e simbólico, como demonstram os exemplos citados, tem caráter prático entrelaçado com o simbólico e o com o econômico. Nesse viés, a terra tem a característica de ser um tipo de seguro de vida por razões óbvias. Um dos agricultores entrevistados expressa o seguinte:

Eso como dicen nuestros abuelos: el varón que se casa que siembre su maíz, su frijol. Es cierto, tampoco te va dar dinero, pero tampoco vas a sufrir de hambre. Podés estar enfermo, podés estar sin trabajo, pero usted sólo viene, y comamos... Pero si no hay trabajo, aunque cueste cien quetzales [GTQ] el quintal [45,35 kg], pero si no tenés los cien quetzales. ¿Qué vas a hacer? Y ajustando. Como dicen algunos, no todos, espero que no esté usted ahí, y no quiero que entre ahí: el estudio que le dejo a mis hijos es su herencia, ¡Dios mío! ¿Vas a comer ese papel? ¿Qué voy a hacer yo ahí? Eso ponéte a analizar. Antes eso se platica entre papá e hijos: -te voy a dar estudio. -Sí papa, ¿pero si me das estudio será que eso va ser mi herencia o sólo va ser para progresar? Y si viene el papá y dice: -mija, mijo, yo sólo quiero verte como un profesional de mi familia, y lo demás sigue lo mismo. Ah, entonces sí. Porque de un profesional no espero nada del trabajo, entonces todo eso hay que ver. Yo todo eso he analizado, por eso con muchos he platicado así, a veces se molestan cuando les digo: bueno, el estudio no es malo, lo malo es que no hay trabajo (Entrevista C02E02, 03/12/2016).

A partir disso, pode-se entender como a falta de terra para as famílias camponesas representa uma vida no limbo:

Bueno lo que pasa aquí en nuestro pueblo, hay dos cosas muy importantes. Hay familias que están superando por la agricultura porque gracias a sus familiares, es posible que el abuelo o el padre de familia de las personas o de las familias, es posible que tiene un exceso de terreno y eso les ha ayudado a ellos para que se superen y hay familias que tienen menos terreno, o que han tenido que hacer el esfuerzo para lograrlo, entonces eso es lo que hace que hay familias más o menos pasan para vivir, para desarrollarse (Entrevista C01E08, 12/02/2017).

Com base nisso, questiona-se o porquê existem famílias camponesas sem terra há pelo menos duas gerações. A resposta não é simples e até se refere à história agrária do país e à história da estrutura econômica colonial. Por outro lado, também a dinâmica do crescimento familiar e demográfico responde à pergunta. Mas, vale ressaltar a indagação sobre quais as perspectivas e opções tem os camponeses que não possuem terras. Sobre o futuro das economias camponesas, a partir desse ponto histórico, ninguém tem uma resposta clara se o acesso à terra e à estrutura fundiária na Guatemala não for modificado, e se as famílias camponesas não se conglomerarem e organizassem em, pelo menos, organizações produtivas que as concedam mais e melhores perspectivas.

Vale destacar que a economia camponesa não se dedica a uma única atividade econômica, baseia-se precisamente na capacidade de cada unidade familiar de se adaptar a diferentes circunstâncias (CHAYANOV, 1974; SHANIN, 1976; WOLF, 1971), porém, mantendo um vínculo com a terra. No momento em que, por qualquer motivo, esse vínculo é quebrado, toda a dinâmica dentro da família é interrompida. Não é que a terra do município esteja completamente esgotada, só que, juntamente com a divisão da terra, cresce cada vez mais um problema. O acesso na forma de arrendamento parece ser a opção, mas deixa de ser uma opção viável para famílias camponesas que vivem na subsistência e à beira da pobreza.

\section{Considerações finais}

O camponês é aquele produtor agrícola rural que imprime o desenvolvimento apenas em uma unidade doméstica produtiva multifuncional, por meio de uma relação de coprodução entre a sociedade (família camponesa) e a natureza. No entanto, para conseguir isso, existe uma condição indispensável, o acesso à terra. Obviamente, essa é uma parte central na reprodução da vida de uma unidade camponesa, ou seja, a terra é o recurso essencial para alcançar a autonomia. E, embora a posse de terra seja determinante na 
organização familiar camponesa, a luta pelo acesso à terra é igualmente indispensável na definição teórica da condição camponesa.

Para alcançar a melhor coprodução possível entre sociedade e natureza, as unidades camponesas devem ordenar sua base de recursos, que tem o acesso à terra como elemento central, de maneira que permita certa autodeterminação. Apesar da posse de terra não ser uma condição necessária para ser considerado camponês nesse contexto, a busca pela autonomia e desenvolvimento para uma unidade doméstica agrícola, que permita perspectivas além da subsistência, sim é uma condição indispensável para se considerar camponês. Portanto, a composição dessa base de recursos é importante, principalmente porque a produção familiar e camponesa é organizada em torno da disponibilidade de terras.

O caso específico do município de Patzicía analisado mostra o fenômeno da pulverização da terra. Sobre os fatores que propiciam a referida pulverização, pode-se dizer que, junto com o crescimento natural da população, a terra é dividida. Entretanto, como observado, essa questão é determinada pelas demandas e lógica do mercado, em que a agricultura do município está imersa.

A pequena produção para o autoconsumo e troca local é o modo de vida em que as unidades camponesas se desenvolvem em Patzicía. As produções em pequenas áreas de terra fazem parte e, ao mesmo tempo, são o resultado de uma dinâmica econômica (mais ampla) nacional capitalista, sujeita a múltiplos vínculos com uma economia global que, entre outras coisas, modifica as relações sociais e econômicas locais, por exemplo, as relações de arrendamento e suas particularidades.

Em outras palavras, a partir do conhecimento da composição da base de recursos do camponês no município, pode-se dizer que dentre os fatores que favorecem a pulverização da terra e, portanto, sua indisponibilidade, há as demandas de mercado, que caem sobre a produção de hortaliças, amplamente difundidas em todo o município, o que torna seu preço extremamente alto. Isso leva os camponeses a entrarem na dinâmica do arrendamento, o que também representa um alto custo para as famílias mais empobrecidas. Com base nisso, pode-se dizer que, juntamente com as consequências do acesso desigual à terra, ou à terra de qualidade, no município, esses são os principais fatores que expulsam aso camponeses em direção à mobilidade ocupacional e às migrações que isso implica, para cidades próximas ou outros países, como a imigração ilegal para os EEUU, e a migração laboral legal temporal para o Canadá, com a consequente precariedade da vida das famílias camponesas.

\section{Referências bibliográficas}

CHAYANOV, A. La organización de la unidad económica campesina. Buenos Aires: Ediciones Nueva Visión. 1947.

FAO. Tenencia de la tierra y desarrollo rural. Disponível em: ftp://ftp.fao.org/docrep/fao/005/y4307S/y4307S00.pdf. Libro electrónico. Roma: Organización de las Naciones Unidas para la Agricultura y la Alimentación. 2006.

GIRONA, J. Los estudios de comunidad. In: PUJADAS, J. (coord.). Etnografía. Barcelona: Editorial UOC, 2010 .

GUATEMAlA. Instituto Nacional de Estadística (INE). III Censo Agropecuario Nacional. Ciudad de Guatemala, 1973.

GUATEMAlA. Instituto Nacional de Estadística (INE). IV Censo Agropecuario Nacional. Ciudad de Guatemala, Tomos I, II e III, 2004.

LÓPEZ, M., Figueroa, J., e Pelaes, C. Diagnostico socioeconómico, potencialidades productivas y propuestas de inversión: Municipio de Patzicía departamento de Chimaltenango. Guatemala: USAC. 2011.

PÉREZ, O., Roca, G. P. de la, Herrera, A. I., López, M. J., Rodas, I., y Rodríguez, A. M. Cambios económicos producidos por la expansión de la horticultura de exportación en la organización social de las configuraciones socioculturales de Patzicía y Zaragoza, Chimaltenango. DIGI y Escuela de Historia. USAC. Guatemala: Llenera. 1991. 
PLOEG, J. D. van der. Nuevos campesinos: campesinos e imperios alimentarios. Barcelona: Icaria Editorial S. A. 2010.

PUJADAS, J. La etnografía como mirada a la diversidad social y cultural. In: PUJADAS, J. (coord.). Etnografía. Barcelona: Editorial UOC, 2010.

RODAS, I. e ESQUIT, E. Elite ladina, vanguardia indígena: de la intolerancia a la violencia, Patzicía 1944. Guatemala: IIHAA. 1997.

SHANIN, T. Naturaleza y lógica de la economía campesina. Barcelona: Editorial Anagrama. 1976.

TOCÓN-AJSIVINAC, E. De lo global a lo local: la economía familiar campesina en Patzicía, 2005-2016. Dissertação de graduação. Escuela de Historia, USAC. 2018.

WOLF, E. Sociedades camponesas. Rio de Janiero: Zahar Editores. 1976.

WOLF, E. Los campesinos. Barcelona: Editorial Labor S. A. 1971.

(1) ; (2) Este artigo é distribuído nos termos e condições do Creative Commons Attributions/AtribuiçãoNãoComercial-CompartilhaIgual (CC B Y-NC-SA). 